\title{
The Effect of Lambda-Doublet Levels in Ethanol Flame Temperature Estimation
}

\author{
Dermeval Carinhana Jr., ${ }^{*}, a$ Luiz G. Barreta, ${ }^{a}$ Celso A. Bertran ${ }^{b}$ and \\ Alberto M. dos Santos ${ }^{a}$ \\ ${ }^{a}$ Divisão de Aerotermodinâmica e Hipersônica, Instituto de Estudos Avançados, CP 6044, \\ 12228-970 São José dos Campos-SP, Brazil \\ ${ }^{b}$ Instituto de Química, Universidade Estadual de Campinas, CP 6154, \\ 13083-970 Campinas-SP, Brazil
}

\begin{abstract}
Temperaturas rotacionais de $\mathrm{CH}^{*}$ em chamas de etanol com diferentes gases diluentes foram determinadas por emissão natural. Estruturas finas do espectro indicaram duas temperaturas rotacionais. Os resultados dos níveis de simetria $\mathrm{A}^{\prime \prime}$ foram ligeiramente maiores que os $\mathrm{A}^{\prime}$. Os valores também indicaram uma distribuição fora de equilíbrio.
\end{abstract}

Rotational temperatures of $\mathrm{CH}^{*}$ species present in ethanol flames with different diluent gas compositions were determined using natural emission spectroscopy. Spectrum fine-structures showed two different rotational temperatures. The results of $\mathrm{A}^{\prime \prime}$ symmetry levels were slightly higher than $\mathrm{A}^{\prime}$ for all flames investigated. The temperature values also indicated a non-equilibrium distribution.

Keywords: chemiluminescence, Boltzmann distribution, combustion diagnostics

\section{Introduction}

Ethanol is pointed as one of the most important alternative fuels for automotive engines. In fact, in Brazil ethanol derived from sugarcane, has been added to gasoline since 1931. ${ }^{1}$ Since then, the amount of added ethanol has grown from 5 to $25 \%$. However, only in 1980 dedicated engines were developed to operate with $100 \%$ ethanol. In 2003, a new generation of engines, named "flex fuel engines", was developed to operate with any proportion of the mixture gasoline-ethanol, or only with one of the two fuels. Other countries, as the United States and Australia, have started similar programs to use ethanol as alternative fuel. ${ }^{2}$

Although ethanol has been employed in large scale as a fuel or as a fuel additive, there are few studies concerning the determination of combustion parameters, among them the temperature and the concentration of intermediate products, such as free radicals. These measurements are important, for example, for analyzing the combustion kinetics and determining the combustion efficiency. ${ }^{3}$ Laser induced fluorescence (LIF) has been used to measure temperature and concentration of $\mathrm{OH}$ and $\mathrm{CH}$ radicals in

*e-mail: dcarinhana@ieav.cta.br ethanol flames. ${ }^{3,4}$ This method is based on laser-induced excitation of a specific species and subsequent measurement of their fluorescence. On the other hand, natural emission, or chemiluminecence, of the species also can be used for temperature measurement of flame..$^{5-7}$

Natural emission spectrum of a species contains electronic, vibrational and rotational information, including temperature data. The latter can be determined using the Boltzmann's method, which is based on the measurement of the relative peak intensities of emission lines of the species spectra. ${ }^{5}$ The relationship between the peak intensity (I) and the temperature $(\mathrm{T})$ results from the Boltzmann population distribution of the excited states. For ro-vibrational spectra, this is given by:

$I=\mathrm{CS}_{\mathrm{J}^{\prime}{ }^{\prime}{ }^{\prime}} \lambda^{-4} \exp \left(\frac{-E_{J^{\prime}}}{k T}\right)$

where $S_{J^{\prime} J^{\prime}}$ is the line strength of a transition from the upper $\left(\mathrm{J}^{\prime}\right)$ to the lower $\left(\mathrm{J}^{\prime \prime}\right)$ rotational state; $\mathrm{E}_{\mathrm{J}^{\prime}}$ is the rotational energy of the upper ro-vibrational level; $\mathrm{C}$, a proportionality constant; $\lambda$ is the line wavelength; and $\mathrm{k}$ is the Boltzmann factor. Then, if the system presents a Boltzmann distribution, a plot of the natural logarithm of 
line intensities as a function of the energy level divided by $\mathrm{k}$ is a straight line, whose slope is the inverse of the rotational temperature.

Generally, rotational temperatures of the intermediate species of atmospheric flames are very close to the system kinetics temperature, which is the most common temperature concept adopted to characterize a flame. This is due to the quick transfer between translational and rotational energies. ${ }^{8}$ In flames, part of the chemical species, such as $\mathrm{CH}^{*}$ radical, are created directly in excited electronic states that decay to lower states, emitting radiation. ${ }^{9}$ Species distribution among discrete energy levels is mainly driven by collisional processes and a Boltzmann distribution is very quickly achieved. In fact, only in low-pressure flames or plasmas, non-Boltzmann distribution is observed. ${ }^{10}$ If the emitted radiation life-time is sufficiently long, equilibrium between rotational modes and translational temperature is achieved by collisions before the spontaneous emission takes place. Thus, if radiation auto-absorbing processes are neglected, as is the case of thin flames, rotational temperature from emission spectrum can be adopted as the flame, or kinetic, temperature. Otherwise, if the life-time is not enough to establish a complete equilibrium between rotational and translational modes, rotational temperature cannot be assumed as flame temperature. In this case, emission spectrum shows a non-equilibrium thermal species distribution and can furnish radical rotational temperatures that are even higher than the adiabatic flame temperature. ${ }^{11}$

Spectra of $\mathrm{CH}^{*}$ between 418 and $425 \mathrm{~nm}$, which correspond to the electronic transition $\mathrm{CH}\left(\mathrm{A}^{2} \Delta\right) \rightarrow \mathrm{CH}\left(\mathrm{X}^{2} \Pi\right)$, is formed predominantly by the R-branch of the $0-0$ vibrational band, which appears as doublet peaks corresponding to rotational levels with total angular momentum $\mathrm{J}$ varying from 11 up to 20 . These electronic states present both $\Lambda$-doubling and spin-orbit splitting. ${ }^{12-15}$ As spin-orbit parameter is small compared with rotational constant, molecular coupling scheme approaches the Hund's case (b). Spin-orbit splitting creates two manifolds of energy levels $F_{1}$ and $F_{2}$, which are associated to the rotational levels $\mathrm{J}=\mathrm{N} "+1 / 2$ and $\mathrm{J} "=\mathrm{N} "-1 / 2$, respectively, where $\mathrm{N}$ " is the total angular momentum excluding the spin. $\Lambda$-doubling produces splitting in each of these $J$ " levels, which originates states of + and - symmetry. For $F_{1}$ manifold, the lower levels are designed by the notation " $\mathrm{f}$ ", while in the $\mathrm{F}_{2}$, the lower split levels are named "e". Additionally, rotational levels can be classified according to wavefunction symmetry. For Hund's case (b) species, as $\mathrm{CH}, \mathrm{F}_{1 \mathrm{e}}$ and $\mathrm{F}_{2 \mathrm{f}}$ show a symmetric behavior with respect to the reflection in the plane of molecule rotation, while $\mathrm{F}_{1 \mathrm{f}}$ and $\mathrm{F}_{2 \mathrm{e}}$ show an antisymmetric. For $\mathrm{CH}$ ground state, these levels are named $\Pi\left(\mathrm{A}^{\prime}\right)$ and $\Pi\left(\mathrm{A}^{\prime \prime}\right)$, respectively. In $\mathrm{CH}$ spectra, for J" $\geq 11, \mathrm{R}_{11 \text { ee }}$ and $\mathrm{R}_{22 \mathrm{ff}}$ lines, where $\mathrm{R}$ is the transition sequence with $\Delta \mathrm{J}=+1$, are spectrally unresolved. The same behavior is observed for $\mathrm{R}_{11 \mathrm{ff}}$ and $\mathrm{R}_{22 \mathrm{ee}}$ lines. Thus, in $\mathrm{CH}$ doublets, peaks with longer wavelengths are associated to the $\mathrm{A}^{\prime}$ symmetry, while those with shorter wavelength are to the $\mathrm{A}^{\prime \prime}$.

In this article, we investigated the effect of $\Lambda$-doublets degenerate energy levels in the $\mathrm{CH}^{*}$ rotational temperature calculation of atmospheric ethanol flames using the natural emission spectroscopy.

\section{Experimental}

Ethanol flames were produced using the combustion system supplied by a gaseous mixture of ethanol/inert gas/oxygen. Ethanol was evaporated using a copper heated coil attached to the burner fuel inlet. The heater working temperature was ca. $110^{\circ} \mathrm{C}$. Inert gases used were nitrogen, carbon dioxide, helium and argon.

The input flows of the gases were controlled by calibrated flowmeters. Ethanol and oxygen flows were set to $25 \times 10^{-3} \mathrm{~mol} \mathrm{~min}^{-1}$ and $40 \times 10^{-3} \mathrm{~mol} \mathrm{~min}^{-1}$, respectively, which produced a fuel rich flame, with a flame equivalence ratio $(\phi)$ equal to 1.5 . Inert gas flows varied from 7.5 to $30 \times 10^{-3} \mathrm{~mol} \mathrm{~min}^{-1}$.

The optical system used consisted of a TRIAX 550 (Jobin Yvon) monochromator of $0.5 \mathrm{~m}$ focal length (f), equipped with a 1200 lines $\mathrm{mm}^{-1}$ diffraction grating, with blaze at $500 \mathrm{~nm}$. A quartz lens, with $\mathrm{f}=100 \mathrm{~mm}$ and diameter of 2" was used for primary light collection. The flame image was projected on a mask with a $1: 1$ magnification, where the light passed through a pinhole and was collected by a fiber optic bundle connected to the spectrometer light entrance. The emission signal was detected by an ICCD camera DICAM-Pro model DP-25-SVGA-P46. Spectra were obtained in the 418 to $427 \mathrm{~nm}$ range, which corresponds to the $\mathrm{A}^{2} \Delta \rightarrow \mathrm{X}^{2} \Pi$ electronic band of the $\mathrm{CH}^{*}$ radical. Spectral resolution obtained was ca. $0.05 \mathrm{~nm}$. All spectra were measured at $1.5 \mathrm{~mm}$ from the outlet of the burner which corresponds to the brighter flame region.

\section{Results and Discussion}

Figure 1 shows $\mathrm{CH}^{*}$ spectra of ethanol flames. We can observe a remarkable difference between the intensities of $\Pi\left(\mathrm{A}^{\prime}\right)$ and $\Pi\left(\mathrm{A}^{\prime \prime}\right) \Lambda$-doublet peaks. However, this difference is not uniform along the spectrum. At longer wavelengths, $\Pi\left(\mathrm{A}^{\prime}\right)$ intensities are higher, while at shorter wavelengths $\Pi\left(\mathrm{A}^{\prime \prime}\right)$ peaks become more intense. The 
wavelengths blueshift observed in Figure 1 of $c a .0 .3 \mathrm{~nm}$ is a calibration artifact of ICCD camera. However, as the temperature determination is based only on the relative intensities of the peaks, this shift does not change our results.

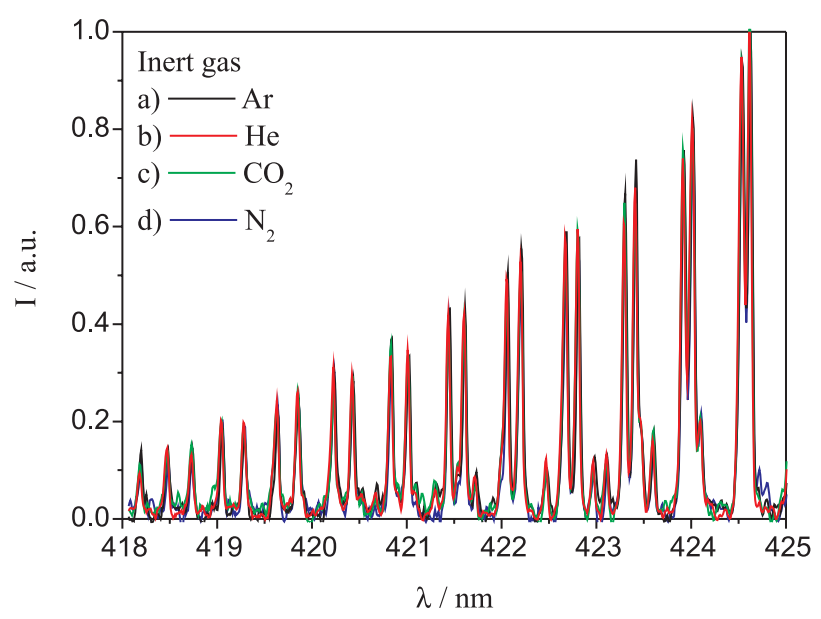

Figure 1. $\mathrm{CH}^{*} \mathrm{~A}-\mathrm{X}$ band spectrum for ethanol flames with a) argon, b) helium, c) carbon dioxide and d) nitrogen as inert gas.

An average measurement of the imbalance of $\Pi\left(\mathrm{A}^{\prime \prime}\right) / \Pi\left(\mathrm{A}^{\prime}\right)$ along $\mathrm{J}^{\prime}$ values is shown in Figure 2. The preferential formation $(\mathrm{P})$ for $\mathrm{A}^{\prime}$ species is defined by the following expression:

$\mathrm{P}\left(\mathrm{A}^{\prime}\right)=\left[\mathrm{I}\left(\mathrm{A}^{\prime}\right)-\mathrm{I}\left(\mathrm{A}^{\prime \prime}\right)\right] /\left[\mathrm{I}\left(\mathrm{A}^{\prime}\right)+\mathrm{I}\left(\mathrm{A}^{\prime \prime}\right)\right]$

where $\mathrm{I}\left(\mathrm{A}^{\prime}\right)$ and $\mathrm{I}\left(\mathrm{A}^{\prime \prime}\right)$ correspond to the spectrum emission signal of the $\Lambda$-doublet peaks.

Results in Figure 2 confirm the preferential formation of $\mathrm{A}^{\prime}$ symmetry species at low $\mathbf{J}$ values, while $\mathrm{A}^{\prime \prime}$ species are preferentially formed at higher J. Rotational temperatures

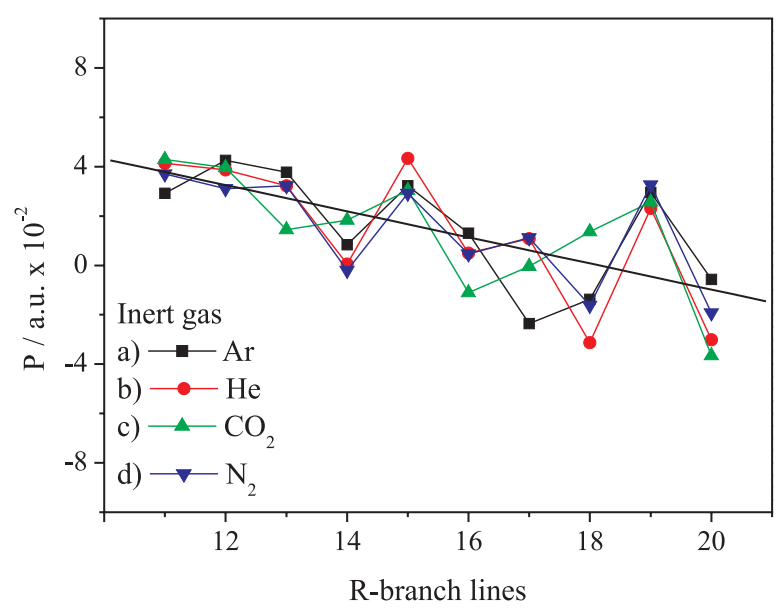

Figure 2. Preferential formation for A' symmetry species along R-branch lines of $\mathrm{CH}^{*}$ spectra of ethanol flames with a) argon, b) helium, c) carbon dioxide and d) nitrogen as inert gas. for ethanol flames were determined from the slope of the straight lines obtained according to equation $1 . \mathrm{S}_{\mathrm{J}^{\prime} \mathrm{J}}$ and $\mathrm{E}_{\mathrm{J}^{\prime}}$ data were taken from the literature. ${ }^{5}$ Figure 3 shows a Boltzmann's plot of ethanol flames with nitrogen flow of $12.5 \times 10^{-3} \mathrm{~mol} \mathrm{~min}^{-1}$. Intensity values from each symmetry kind of the $\Lambda$-doublet peaks were used. The contribution of 1-1 vibrational band, mainly observed in the peaks with $\mathrm{J}=11$ and $\mathrm{J}=12$, were excluded by applying the deconvolution procedure based on the program LIFBASE. ${ }^{16}$ The fitted points correspond to the average of four experimental $\mathrm{CH}^{*}$ spectra. Errors are the standard deviation of the measurements.

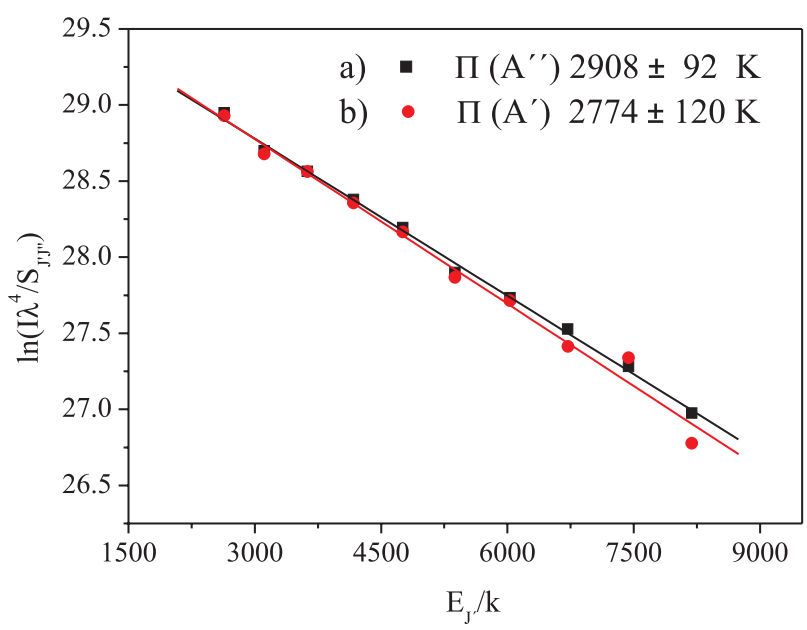

Figure 3. Boltzmann's plot for ethanol flames with argon flow of $12.5 \times 10^{-3} \mathrm{~mol} \mathrm{~min}^{-1}$. Calculated rotational temperatures were a) $2908 \mathrm{~K} \pm 92 \mathrm{~K}$ for $\Pi\left(\mathrm{A}^{\prime \prime}\right)$ peaks and b) $2774 \mathrm{~K} \pm 120 \mathrm{~K}$ for $\Pi\left(\mathrm{A}^{\prime}\right)$ peaks. Temperature errors were calculated by standard deviation from four flame spectra.

Plot linearity in Figure 3 indicates that each $\mathrm{CH}^{*} \Lambda$-doublet population showed a Boltzmann's distribution. However, spectra fine-structures, i.e., $\Lambda$-doublet levels, showed a slight difference in the measured rotational temperatures, $2908 \pm 92 \mathrm{~K}$ for $\Pi\left(\mathrm{A}^{\prime \prime}\right)$ and $2774 \pm 120 \mathrm{~K}$ for $\Pi\left(\mathrm{A}^{\prime}\right)$ levels. In literature, as far as we could find, only $\Pi\left(\mathrm{A}^{\prime}\right) \Lambda$-doublet peaks were used for temperature determination using emission spectroscopy, but our results suggest that their rotational population distribution is not equivalent to the $\Pi\left(\mathrm{A}^{\prime \prime}\right) .^{5,17}$ Table 1 shows rotational temperatures determined for all the gas mixtures.

Results in Table 1 show that rotational temperature values determined by $\Lambda$-doublet peaks of each symmetry are not identical. This suggests that the distribution of the chemiluminescent $\mathrm{CH}^{*}$ population distribution along the $\mathrm{J}^{\prime}$ values is not equal for each symmetry species. Higher temperatures indicate that the higher rotational levels are more populated. These results indicate that temperature inequality is related with the formation processes of the two symmetry species of $\mathrm{CH}^{*}$ radical. 
Table 1. Rotational temperatures for ethanol flames with nitrogen, helium, argon and carbon dioxide as inert gas. Temperature errors are the standard deviation from four spectra

\begin{tabular}{|c|c|c|c|c|c|c|c|}
\hline \multicolumn{2}{|c|}{ Inert gas / $\left(10^{-3} \mathrm{~mol} \mathrm{~min}^{-1}\right)$} & \multirow{2}{*}{$\frac{\mathrm{T} /(\mathrm{K}) \Pi\left(\mathrm{A}^{\prime \prime}\right)}{3010 \pm 117}$} & \multirow{2}{*}{$\frac{\mathrm{T} /(\mathrm{K}) \Pi\left(\mathrm{A}^{\prime}\right)}{2908 \pm 110}$} & \multicolumn{2}{|c|}{ Inert gas / $\left(10^{-3} \mathrm{~mol} \mathrm{~min}^{-1}\right)$} & \multirow{2}{*}{$\frac{\mathrm{T} /(\mathrm{K}) \Pi\left(\mathrm{A}^{\prime \prime}\right)}{2903 \pm 105}$} & \multirow{2}{*}{$\frac{\mathrm{T} /(\mathrm{K}) \Pi\left(\mathrm{A}^{\prime}\right)}{2859 \pm 101}$} \\
\hline $\mathrm{N}_{2}$ & 10.0 & & & $\mathrm{He}$ & 10.0 & & \\
\hline & 12.5 & $2908 \pm 92$ & $2774 \pm 120$ & & 12.5 & $2787 \pm 85$ & $2760 \pm 80$ \\
\hline & 15.0 & $2926 \pm 94$ & $2861 \pm 115$ & & 15.0 & $2878 \pm 80$ & $2871 \pm 90$ \\
\hline & 17.5 & $2855 \pm 117$ & $2757 \pm 71$ & & 17.5 & $2801 \pm 117$ & $2710 \pm 76$ \\
\hline & 20.0 & $2767 \pm 84$ & $2796 \pm 128$ & & 20.0 & $2855 \pm 114$ & $2730 \pm 68$ \\
\hline & 22.5 & $2855 \pm 99$ & $2767 \pm 115$ & & 22.5 & $2739 \pm 79$ & $2650 \pm 86$ \\
\hline & 25.0 & $2713 \pm 80$ & $2657 \pm 75$ & & 25.0 & $2712 \pm 85$ & $2637 \pm 115$ \\
\hline & 27.5 & $2874 \pm 115$ & $2689 \pm 107$ & & 27.5 & $2718 \pm 106$ & $2617 \pm 80$ \\
\hline & 30.0 & $2949 \pm 184$ & $2835 \pm 120$ & & 30.0 & $2636 \pm 60$ & $2628 \pm 99$ \\
\hline \multirow[t]{8}{*}{$\mathrm{Ar}$} & 12.5 & $2968 \pm 157$ & $2861 \pm 93$ & $\mathrm{CO}_{2}$ & 10.0 & $2946 \pm 168$ & $2749 \pm 91$ \\
\hline & 15.0 & $2766 \pm 91$ & $2898 \pm 89$ & & 12.5 & $2882 \pm 147$ & $2980 \pm 172$ \\
\hline & 17.5 & $2804 \pm 89$ & $2837 \pm 100$ & & 15.0 & $3026 \pm 161$ & $2747 \pm 158$ \\
\hline & 20.0 & $2774 \pm 75$ & $2785 \pm 86$ & & 17.5 & $3345 \pm 323$ & $3155 \pm 162$ \\
\hline & 22.5 & $2815 \pm 83$ & $2796 \pm 91$ & & 20.0 & $2991 \pm 296$ & $3083 \pm 191$ \\
\hline & 25.0 & $2871 \pm 106$ & $2750 \pm 93$ & & & & \\
\hline & 27.5 & $2720 \pm 72$ & $2658 \pm 83$ & & & & \\
\hline & 30.0 & $2765 \pm 106$ & $2718 \pm 92$ & & & & \\
\hline
\end{tabular}

Similar results can be found in literature. The LIF spectroscopy of the $\mathrm{CH}$ radical production by the multiphoton dissociation of mixtures of $\mathrm{CH}_{3} \mathrm{I}$ and $\mathrm{Xe}$ in $\mathrm{H}_{2}$ as carrier gas with $\mathrm{ArF}$ laser beam showed that species population in rotational levels cannot be described by a unique rotational temperature. For rotational levels $\mathrm{N} \geq 8$ the population of $\Pi\left(\mathrm{A}^{\prime \prime}\right)$ levels is greater than $\Pi\left(\mathrm{A}^{\prime}\right)$ by a factor of 10. However, results were not conclusive whether this is due to the photochemistry of $\mathrm{CH}$ production and/or to collisional processes. ${ }^{18}$ Experiments based on LIF spectrum of nascent $\mathrm{CH}\left(\mathrm{X}^{2} \Pi\right)$ recorded after $0.3 \mu$ s of photolysis of ketene in low partial pressure condition ( $c a .4 \mathrm{~Pa}$ ) and argon as collider gas $(c a .667 \mathrm{~Pa})$ also showed a very high ratio of $\Pi\left(\mathrm{A}^{\prime \prime}\right) / \Pi\left(\mathrm{A}^{\prime}\right)$ level population for higher rotational quantum number $\left(\mathrm{N}^{\prime \prime}\right) \geq 12 .{ }^{12}$ We calculated the rotational temperatures using Boltzmann's plot method from the relative intensities of both $\Lambda$-doublet levels (Figure 4). A poor-Boltzmann distribution was observed for both $\Pi\left(\mathrm{A}^{\prime \prime}\right)$ and $\Pi\left(\mathrm{A}^{\prime}\right)$ peaks. This behavior is due to the low-pressure condition in which LIF spectrum was obtained. However, a slight Boltzmann behavior is observed at higher $\mathrm{N}^{\prime \prime}$ values. This interval, between R15 and R20 lines, was used for rotational temperature determination.

The values obtained were $2260 \mathrm{~K}$ and $1982 \mathrm{~K}$, for $\Pi\left(\mathrm{A}^{\prime \prime}\right)$ and $\Pi\left(\mathrm{A}^{\prime}\right) \Lambda$-doublet peaks, respectively, and confirm a direct relationship between the relation of $\mathrm{A}^{\prime \prime}$ and $\mathrm{A}^{\prime}$ populations and the abnormal $\mathrm{CH}$ rotational temperatures. However, in the same work, LIF spectra

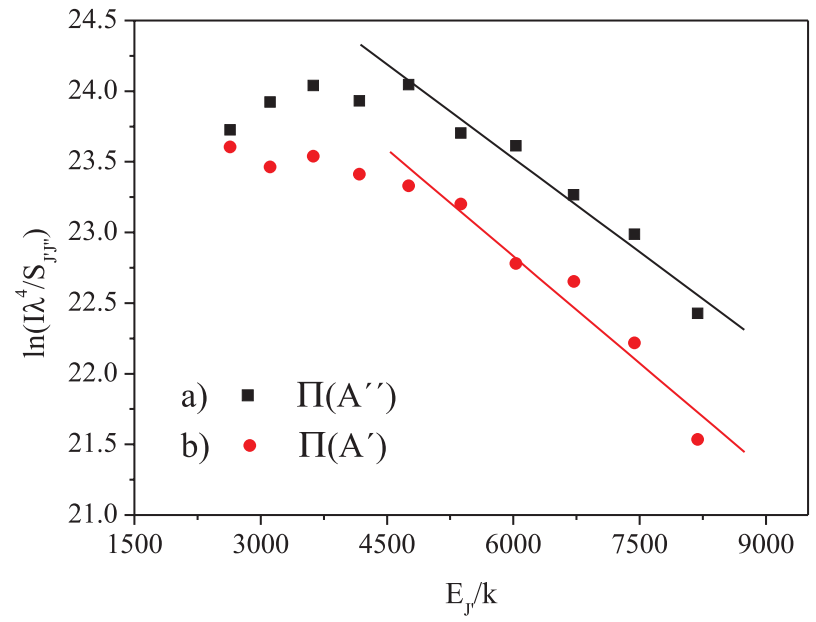

Figure 4. Boltzmann's plot draw from low-pressure $\mathrm{CH}$ spectrum available from literature. ${ }^{14}$ Rotational temperatures for a) $\Pi\left(\mathrm{A}^{\prime \prime}\right)$ and b) $\Pi\left(\mathrm{A}^{\prime}\right) \Lambda$-doublet peaks were, respectively, $2260 \mathrm{~K}$ and $1982 \mathrm{~K}$. Linear fits were calculated using R15-R20 peaks interval.

of nascent $\mathrm{CH}$ obtained in the absence of argon showed a slight imbalance of $\Pi\left(\mathrm{A}^{\prime \prime}\right) / \Pi\left(\mathrm{A}^{\prime}\right)$ for $\mathrm{N}^{\prime \prime} \geq 12$, with rotational temperatures of $2116 \mathrm{~K}$ and $2099 \mathrm{~K}$, respectively. These results suggest that, besides of $\mathrm{CH}^{*}$ chemiluminescent formation, the difference of rotational temperatures observed for $\Lambda$-doublet peaks is also associated with collisional processes.

The interaction of the two symmetry species, $\mathrm{A}^{\prime}$ and $\mathrm{A}^{\prime \prime}$, during a collision is subject to quantum interference effects which results in remarkable differences in the 
collisional behavior of the $\Lambda$-doublet peaks. ${ }^{14}$ Fine-structure state cross section calculations for $\mathrm{CH}$ species showed a clear preference for the production of $\Pi\left(\mathrm{A}^{\prime \prime}\right)$ states. ${ }^{17}$ Additionally, the ratio of $\Pi\left(\mathrm{A}^{\prime \prime}\right) / \Pi\left(\mathrm{A}^{\prime}\right)$ states changes with rotational levels: for higher $\mathrm{N}^{\prime \prime}$ values, a more pronounced ratio is observed.

Other studies showed similar results. The imbalance between $\Pi\left(\mathrm{A}^{\prime \prime}\right)$ and $\Pi\left(\mathrm{A}^{\prime}\right)$ levels and, as consequence, the difference of emission intensity and the abnormal rotational temperature observed in $\mathrm{CH}$ spectrum, is caused by two distinct phenomena: collisional depletion of $\mathrm{A}^{\prime}$ levels and the preferential formation of $\Pi\left(\mathrm{A}^{\prime \prime}\right) .{ }^{13}$ In the first assumption, if we considered a Hund's case (a) coupling limit, whose spin-orbit splitting is much higher than the rotational line spacing, quantum mechanics predicts that collisional processes cannot produce an asymmetry in population distribution in $\Lambda$-doublet levels. ${ }^{13}$ However, in case (b) limit, this symmetry does not hold. $\mathrm{CH}\left(\mathrm{A}^{2} \Delta\right.$, $\mathrm{v}=0$ ) rotational levels closely approach Hund's case (b) limit because of small spin-orbit constant and large rotational constant. ${ }^{19}$ In fact, LIF studies of $\mathrm{CH}\left(\mathrm{A}^{2} \Delta\right.$, $\left.v=0 \Leftrightarrow X^{2} \Pi, v=0\right)$ transition showed that for high rotational quantum number, $\mathrm{N} \geq 11$, the total removal cross sections of $\Pi\left(\mathrm{A}^{\prime}\right)$ levels in electronic excited $\mathrm{CH}\left(\mathrm{A}^{2} \Delta\right)$ radical are much larger than $\Pi\left(\mathrm{A}^{\prime \prime}\right)$ when $\Delta \mathrm{N}=-1$, and a population depletion of $\Pi\left(\mathrm{A}^{\prime}\right)$ levels are observed. ${ }^{20}$ On the other hand, cross sections calculations for $\mathrm{CH}$ radical predict a preferential transition into $\mathrm{A}^{\prime \prime}$ levels for lower $\mathrm{N}$ manifolds during collisional processes. ${ }^{13,20}$ Thus, the abnormal intensity emission and rotational temperatures of $\Pi\left(\mathrm{A}^{\prime \prime}\right) / \Pi\left(\mathrm{A}^{\prime}\right)$ levels can be ascribed to two distinct phenomena: higher collisional depletion of $\Pi\left(\mathrm{A}^{\prime}\right)$ levels and the preferential formation of $\Pi\left(\mathrm{A}^{\prime \prime}\right)$.

Further discussion can be extended to support our rotational temperature results. No appreciable influence of inert gas in $\Lambda$-doublet peak intensities was also observed in Figure 1. Considering the flow range investigated, no influence of the gas amount was also observed. This indicated that, in atmospheric pressure conditions, cross section values for all inert gases are constant and quite equivalent. $\mathrm{OH}^{*}$ LIF absorption measurements of similar ethanol flames showed rotational temperatures ca. $20 \%$ lower than our results. ${ }^{21}$ This means that $\Lambda$-doublet rotational temperature represents a "hot" distribution of chemiluminescent $\mathrm{CH}^{*}$ and cannot be related directly to the flame temperature. This behavior is quite different of our past results from GLP flames, where the $\mathrm{CH}^{*}$ rotational temperatures were much closer to the flame temperatures. ${ }^{6}$ One possible explanation for this is the presence of a kinetic effect in the $\mathrm{CH}^{*}$ chemiluminescent mechanism in ethanol flames, i.e., the mechanistic path of this radical leads to an excited population that is not completely deactivated before spontaneous emission. To test this hypothesis, $\mathrm{CH}^{*}$ LIF measurements will be carried out in ethanol flames. As in this technique the starting point is the radical population of fundamental state, the occasional excited state effect can be discarded and only the deactivation process can be evaluated.

Finally, argon flames showed, in general, the nearest values of $\Lambda$-doublet rotational temperatures, while nitrogen flames showed the largest difference between them. This may suggest that argon presents the lowest difference between the cross-section ratio for $\Lambda$-doublet levels. In fact, the relaxation efficiency of this collider gas is lower than carbon oxide and nitrogen, while the latter shows the largest value. ${ }^{22}$ However, the $\Lambda$-doublet rate constants for energy transfer out of $\mathrm{CH}\left(\mathrm{A}^{2} \Delta, \mathrm{v}=0\right)$ calculated for the three former gases showed that argon presents the highest difference between both $\Lambda$-doublet levels. So, at the moment, our data is not conclusive.

\section{Conclusions}

Abnormal $\Lambda$-doublet rotational temperatures observed in $\mathrm{CH}^{*}$ spectra is caused by difference in collisional behavior of the molecule symmetry species. As consequence, a higher collisional depletion of $\Pi\left(\mathrm{A}^{\prime}\right)$ levels and a preferential formation of $\Pi\left(\mathrm{A}^{\prime \prime}\right)$ is observed in rotational manifolds. No influence of diluents gases was observed. The comparison with LIF data also showed that our natural emission results are $c a$. $20 \%$ higher. Thus, $\mathrm{CH}^{*}$ rotational temperatures cannot be assumed directly as the flame temperature.

\section{References}

1. Moreira, J. R.; Goldemberg, J.; Energy Policy 1999, 27, 229.

2. Niven, R. K.; Renew. Sustain. Energ. Rev. 2005, 9, 235.

3. Boyarshinov, B. F.; Titkov, V. I.; Fedorov, S. Y.; Combust. Expl. Shock Waves 2005, 41, 297.

4. Boyarshinov, B. F.; Fedorov, S. Y.; Combust. Expl. Shock Waves 2003, 39, 379; Khose-Höinghaus, K.; Atakan, B.; Lamprecht, A.; Alatorre, G. G.; Kamphus, M.; Kasper, T.; Liu, N.-N.; Phys. Chem. Chem. Phys. 2002, 4, 2056.

5. Kim, J. S.; Cappelli, M. A.; J. Appl. Phys. 1998; 84, 4595.

6. Carinhana Jr., D.; Barreta, L. G.; Rocha, C. J.; Santos, A. M. dos; Bertran, C. A.; J. Braz. Chem. Soc. 2008, 19, 1326.

7. Lapworth, K. C.; J. Phys. E: Sci. Instrum. 1974, 7, 413; Higgins, B.; McQuay, M. Q.; Lacas, F.; Rolon, J. C.; Darabiha, N.; Candel, S.; Fuel 2001, 80, 67.

8. Couris, S.; Anastasopoulou, N.; Fotakis, C.; Chem. Phys. Lett. 1994, 223, 516. 
9. Smith, G. P.; Luque, J.; Park, C.; Jeffries, J. B.; Crosley, D. R.; Combust. Flame 2002, 131, 59.

10. Mori, H.; Niimi, T.; Akiyama, I.; Tsuzuki, T.; Phys. Fluids 2005, 17, 117103.

11. Bechtel, J. H.; Appl. Opt. 1979, 18, 2100.

12. Ball, S. M.; Hancock, G.; Heal, M. R.; J. Chem. Soc., Faraday Trans. 1994, 90, 1467.

13. Alexander, M. H.; Dagdigian, P. J.; J. Chem. Phys. 1994, 101, 7468.

14. Nizamov, B.; Dagdigian, P. J.; Tzeng, Y.-R.; Alexander, M. H.; J. Chem. Phys. 2001, 115, 800 .

15. Kind, M.; Stuhl, F.; Tzeng, Y.-R.; Alexander, M. H.; Dagdigian, P. J.; J. Chem. Phys. 2001, 114, 4479; Gaydon, A. G.; Wolfhard, H. G.; Flames, $3^{\text {rd }}$ ed., Chapman and Hall: London, 1970.

16. Luque, J.; Crosley, D. R.; LIFBASE; Database and Spectral Simulation (version 1.5); SRI International Report MP 99-009: USA, 1999.
17. Broida, H. P.; J. Chem. Phys. 1953, 21, 340.

18. Macdonald, R. G.; Liu, K.; J. Chem. Phys. 1989, 91, 821.

19. Bernath, P. F.; Brazier, C. R.; Olsen, T.; Hailey, R.; Fernando, W. T. M. L.; Woods, C.; Hardwick, J. L.; J. Mol. Spectrosc. 1991, 147, 16.

20. Heinrich, P.; Stuhl, F.; J. Chem. Phys. 1995, 102, 618.

21. Santos, L. R. dos; PhD Thesis, Universidade de São Paulo, Brasil, 2005; Marques, C. S. T.; dos Santos, L. R.; Sbampato, M. E.; Barreta, L. G.; dos Santos, A. M.; Quim. Nova 2009, 32, 2073.

22. Crichton, H. J.; Murray, C.; McKendrick, K. G.; Phys. Chem. Chem. Phys. 2002, 4, 5768.

Submitted: Nevember 12, 2009

Published online: May 24, 2010

FAPESP has sponsored the publication of this article. 